\title{
Electrogastrographic study of gastric myoelectrical activity in patients with unexplained nausea and vomiting
}

\author{
H GELDOF, E J VAN DER SCHEE, M VAN BLANKENSTEIN, AND J L GRASHUIS \\ From the Departments of Internal Medicine and Medical Technology, Erasmus University, Rotterdam, The \\ Netherlands
}

SUMMARY Using cutaneous electrodes an electrogastrographic study was made of gastric myoelectrical activity in both the fasting and postprandial states in 48 patients with unexplained nausea and vomiting and in 52 control subjects. A gastric emptying study, using a radio-labelled solid phase meal, was carried out in 30 of these 48 patients. A follow up study was done after one year. In $48 \%$ of the patients abnormal myoelectrical activity was found which was characterised by: (1) instability of the gastric pacemaker frequency; (2) tachygastrias in both the fasting and postprandial states; (3) the absence of the normal amplitude increase in the postprandial electrogastrogram. This last characteristic was correlated with a delayed gastric emptying of solids. The present study shows that with electrogastrography in a heterogeneous group of patients with unexplained nausea and vomiting a subgroup can be discerned with abnormal myoelectrical activity. Our findings suggests that this abnormal myoelectrical activity is related to these symptoms.

Patients with 'unexplained' nausea and vomiting, which are often accompanied by belching, epigastric bloating, early satiety and sometimes symptoms of the lower gastrointestinal tract such as constipation and diarrhoea, constitute a heterogeneous group. Although the two main symptoms are suggestive of disturbed gastric motility, an overlap with other disorders, such as the irritable colon syndrome or rumination, cannot be excluded. Myoelectrical activity plays an important role in the control of gastrointestinal motility, therefore investigation of gastric myoelectrical activity may be helpful in identifying gastric motor disturbances. ${ }^{1-5}$

The stomach has an inherent rhythmic myoelectrical activity with a repetition frequency of about $0.05 \mathrm{~Hz}$, which is referred to as electrical control activity. ${ }^{7}$ When motor activity is present, the electrical control activity is accompanied by a second component, with or without superimposed fast oscillating potential changes, referred to as electrical response activity. ${ }^{7}$

Address for correspondence: $\mathrm{E}$ J van der Schee, Department of Medical Technology. Erasmus University. PO Box 1738. 30(0) IDR Rotterdam. The Netherlands.

Received for publication 11 October 1985
The most frequent dysrhythmias described in patients with unexplained nausea and/or vomiting are the so called tachygastrias, typified by electrical control activity frequencies two to four times higher than normal. ${ }^{1-5}$ The studies cited were undertaken using either peroral (suction) electrodes or serosal electrodes placed at laparotomy and recordings were made only in the fasting state. Such invasive methods, however, are not very suitable for the study and follow up of a large group of patients. An extra disadvantage of recordings with peroral suction electrodes is that it is uncertain whether this method is reliable in the postprandial state.

Gastric myoelectrical activity can be recorded in a non-invasive way by means of electrodes attached to the abdominal skin. This method is known as electrogastrography and the recorded signal as an electrogastrogram. Electrogastrography allows the recording of gastric myoelectrical activity in both the fasting and postprandial states, providing information about the gastric electrical control activity frequency, electrical response activity and tachygastrias. $^{\text {. }-16}$

In the present study gastric myoelectrical behaviour was recorded by electrograstrography in both the fasting and postprandial states in patients 
with prolonged, unexplained nausea and vomiting. Gastric emptying of solids was also measured to determine whether abnormal myoelectrical behaviour was associated with a delay in this gastric emptying. A follow up study was done after about one year.

\section{Methods}

\section{PATIENTS}

Forty eight patients (17 men and 31 women, mean age 42 years, range 18-71 years) participated in the study. All 48 patients complained of frequent (more than three times a week) nausea and vomiting, accompanied by one or more of the following symptoms: belching, abdominal distension, sense of fullness after a normal meal, and inability to finish a normal meal. The symptoms, for which no organic cause had been found, had lasted for at least three months (median nine months, range 3-62 months). The diagnostic workup included a clinical evaluation, appropriate laboratory tests, ultrasound scanning of the upper abdomen, and upper gastrointestinal endoscopy.

Thirty of the 48 patients consented to a gastric emptying study using a radio labelled solid phase meal as described in detail by Akkermans et $\mathrm{al}^{17}$ and Jacobs et al. ${ }^{18}{ }^{19}$ Gastric emptying was considered to be delayed if the percentage emptied in one hour was more than two standard deviations below the mean of control subjects. ${ }^{19}$ Exclusion criteria were a history of systemic illness - for example, diabetes mellitus, rheumatic disorders or vasculitus, neurological or psychiatric disorders, or previous gastrointestinal or biliary surgery. Patients taking any drug were excluded, with the exception of those taking gastrointestinal prokinetic drugs such as metoclopramide or domperidone, which were stopped at least one week before the electrograstrography and gastric emptying study.

In 36 patients a follow up study after about one year (range 11-13 months) was possible. The gastric emptying study was repeated in those patients in whom this had initially been carried out (20 patients).

Control subjects were 27 men and 25 women (mean age 42 , range 16-75 years) without any history of gastrointestinal or systemic disorder. The study was approved by the Medical Ethics Committee of the Erasmus University, Rotterdam, on 4 June, 1982 and carried out with the informed consent of the subjects.

\section{TECHNIQUE OF RECORDING}

Although in most subjects an optimal electrode direction coincides with the antral axis, ${ }^{20}$ the opti-

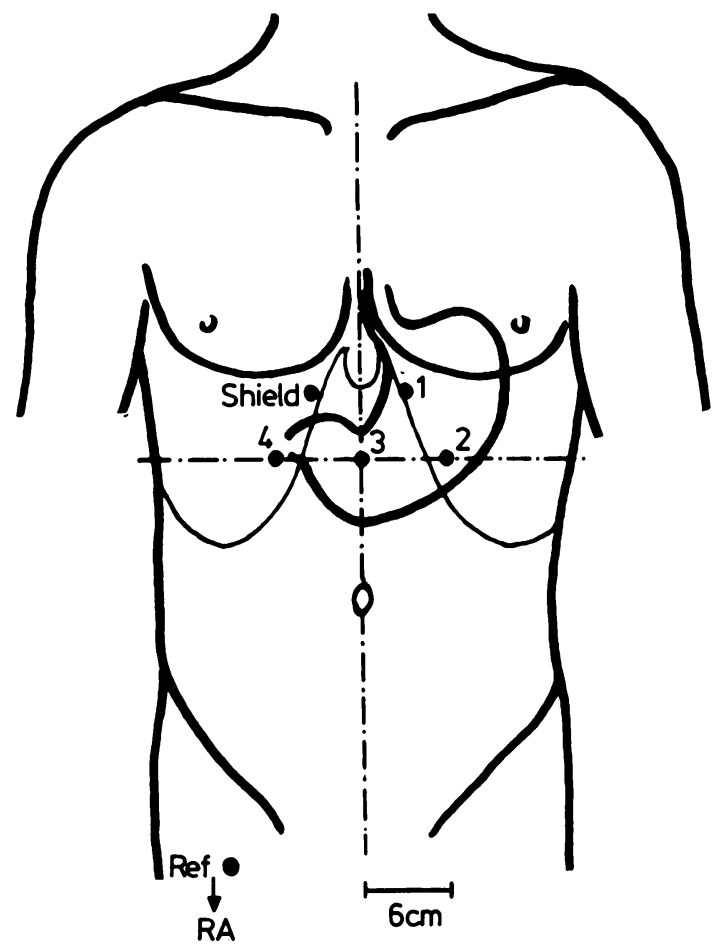

Fig. 1 Electrode positions used in this study. Electrodes 2, 3 and 4 are situated on a transverse line halfway between the lower end of the sternum and the umbilicus. Electrode 3 is placed at the intersection of this line and the median plane. Distance between all abdominal electrodes is $6 \mathrm{~cm}$.

Reference electrode is on the right ankle (RA). The shield electrode was used to reduce possible interference from the $50 \mathrm{~Hz}$ mains voltage at the input stage of the preamplifiers.

mum electrode position cannot be defined exactly because of interindividual anatomical variations. $^{21} 22$ Therefore several leads were used and the signal with the best signal to noise ratio was then selected for further analysis. In this choice contamination of the signal with a respiration component is of less importance than are large motion artefacts, which occur in particular in the monopolar leads. The positions of the six recessed type electrodes (Red Dot 2256, 3M Co.) used in this study are shown in Fig. 1. A strain gauge respiration transducer was attached to the thoracic wall. Activity during fasting was recorded for a 30 minute period after an overnight fast. A test meal consisting of $250 \mathrm{ml}$ yoghurt with $20 \mathrm{~g}$ sugar was then given, and consumed within four minutes, while the recording was continued. The composition of the test meal was: $990 \mathrm{~kJ}, 8.75 \mathrm{~g}$ protein, $8.75 \mathrm{~g}$ fat, and $30 \mathrm{~g}$ carbohydrate. The recording was stopped $35 \mathrm{~min}$ 
after the start of the test meal. Subjects lay quietly in a supine position during most of the recording session (only sitting up while taking the test meal). The four monopolar and six bipolar signals were recorded on paper (Van Gogh EP-8b) and simultaneously stored on magnetic tape (Racall Store 14). The high and low pass filters ( 6 decibel/octave) were set at 0.01 and $0.5 \mathrm{~Hz}$ respectively. ${ }^{21}$

SIGNAL ANALYSIS

A fast Fourier transform algorithm implemented on a NOVA 2 digital computer was used to obtain power spectra of the time signals. The signals, replayed from tape 16 times faster than real time, were preprocessed by band-pass filtering using a Butterworth filter ( 24 decibel/octave) with (real time) cut-off frequencies set at 0.01 and $0.5 \mathrm{~Hz}$, to remove possible DC components and to avoid aliasing. They were then digitised (real time sampling frequency $1 \mathrm{~Hz}$ ) and fed into the computer. The time signal of the whole recording period was used for signal analysis. Spectra were obtained as follows: every $64 \mathrm{~s}$ a power spectrum was computed from the preceeding $256 \mathrm{~s}$ of the electrogastrographic timesignal, to which a Hamming window had been applied to reduce leakage. ${ }^{23}$ These time values have been shown to enable the extraction of relevant information from the electrogastrogram, giving 129 points/spectrum and a frequency spacing of $0.0039 \mathrm{~Hz} .{ }^{16}$ Tachygastrias which have a duration of at least $64 \mathrm{~s}$ can be detected using these time values. ${ }^{16}$ This procedure generates a series of overlapping spectra, called running spectra. They were plotted in two different ways, using pseudo-3-dimensional and grey-scale plots. The grey-scale plot, in particular, enables the easy recognition of frequency patterns. Relative power changes can be recognised more precisely in the pseudo-3-dimensional plot. Plots were made on a Versatec 1100 A printer plotter. The mean gastric frequency $(\mathrm{Hz})$ with standard deviation and its power content were computed for both the fasting and postprandial states. An instability factor was calculated to give a measure of the variability in the electrical control activity frequency visible in grey-scale plots. This was defined as the ratio of the frequency standard deviation of the whole fasting or postprandial period to the frequency standard deviation of one, arbitrary chosen, spectrum containing a clearly present gastric frequency component in the fasting or postprandial state respectively.

Because the absolute value of the amplitude $(\mathrm{mV})$ of a recorded cutaneous signal (and thus its power content) is influenced by a number of factors - for example, electrode-skin resistance, tissue conductivity, electrode distance to the stomach wall, it is impossible to make a comparison of interindividual and even intra-individual power data. Therefore in this study only power changes in one single recording session were used for analysis. To quantify the postprandial power change, the ratio of the power in the postprandial state to the power in the fasting state was computed and referred to as the power ratio.

Where it was considered to be necessary running spectrum analysis of the respiration signal was done to exclude confusion between frequencies of respiratory origin and possible tachygastrias.

The only parameter associated with the electrogastrographic waveform that was used in this study was the presence of a second harmonic in the spectrum. Higher harmonics can be recognised in the spectrum because their frequency spacing forms exactly an integer. The more a periodic signal deviates from a sinusoid, the more harmonics may be expected to be present. A second harmonic of the gastric frequency was considered to be present if its power amounted to at least $5 \%$ of the power of the first harmonic - that is, the gastric frequency itself.

\section{STATISTICAL ANALYSIS}

Dichotomised data were compared using Fischer's exact test. To compare continuous data between groups the Mann-Whitney U-test (non-parametric) was used. Regression lines (least square method) and coefficients of correlation ( $r$ ) were calculated for normally distributed data, otherwise the Spearman rank correlation coefficient was calculated. Probability $(p)$ values were derived from two-tailed tests with 0.05 being taken as the significant level.

\section{Results}

A total of 136 standard recordings were made in 100 subjects. In the control group $3 \cdot 1 \%$ of the total recording time (the initial two to three spectra after food intake) could not be interpreted because of motion artefacts during food intake. In the patient group $4.7 \%$ of the recording time was lost as the result of artefacts caused by food intake and vomiting.

\section{CONTROL GROUP}

The results in the control group are summarised in Table 1. In the fasting state a gastric electrical control activity frequency of relatively low power was found with negligible frequency variations, as was indicated by an instability factor close to 1 . Immediately after the test meal a frequency dip was observed in every subject. The average frequency decrease was $23 \%$ of the fasting frequency. After about five minutes the frequency started to increase 
Table 1 Electrogastrographic parameters in the control group and in patients with unexplained nausea and vomiting. The division of the patients into subgroups was based on the normal ranges found in the control group. If the postprandial instability factor or power ratio exceeded the normal range the electrogastrogram was considered abnormal. Tachygastrias were also considered abnormal.

\begin{tabular}{|c|c|c|c|}
\hline & \multirow[b]{2}{*}{$\begin{array}{l}\text { Control } \\
\text { group } \\
n=52\end{array}$} & \multicolumn{2}{|l|}{ Patient group $n=48$} \\
\hline & & $\begin{array}{l}\text { Normal } \\
\text { electrogastrogram } \\
n=25\end{array}$ & $\begin{array}{l}\text { Abnormal } \\
\text { electrogastrogram } \\
n=23\end{array}$ \\
\hline Age (yr) & $\begin{array}{l}36 \\
16-75\end{array}$ & $\begin{array}{l}39 \\
18-71\end{array}$ & $\begin{array}{l}47 \\
8-66\end{array}$ \\
\hline $\begin{array}{l}\text { Duration } \\
\text { complaints (mo) }\end{array}$ & & $\begin{array}{l}10 \\
3-62\end{array}$ & $\begin{array}{l}12 \\
3-60\end{array}$ \\
\hline \multicolumn{4}{|l|}{ Fasting } \\
\hline Frequency & 0.050 & 0.049 & $0 \cdot 051$ \\
\hline $\mathrm{Hz}$ & $0.045-0.055$ & $0.045-0.055$ & $0.045-0.059$ \\
\hline Instability & $1 \cdot 12$ & $1 \cdot 14$ & $1 \cdot 20$ \\
\hline factor & $1 \cdot 00-1 \cdot 40$ & $1.00-1.39$ & $1 \cdot 00-3 \cdot 10$ \\
\hline Second harmonic \% & $38 \cdot 5$ & 44 & $60 \cdot 9$ \\
\hline Tachygastrias & 0 & 0 & 6 \\
\hline \multicolumn{4}{|l|}{ Postprandial } \\
\hline Frequency & 0.054 & 0.052 & 0.051 \\
\hline $\mathrm{Hz}$ & $0.047-0.064$ & $0.047-0.058$ & $0.042-0.060$ \\
\hline Instability & $1 \cdot 10$ & $1 \cdot 10$ & 2.05 \\
\hline factor & $1 \cdot 00-1 \cdot 40$ & $1.00-1.37$ & $1.00-4.00$ \\
\hline Second harmonic \% & $67 \cdot 3$ & 72 & $17 \cdot 4^{*}$ \\
\hline Power & $6 \cdot 79$ & $4 \cdot 13$ & 0.87 \\
\hline ratio & $2 \cdot 08-16 \cdot 61$ & $2 \cdot 09-16 \cdot 01$ & $0 \cdot 17-15 \cdot 06$ \\
\hline Tachygastrias & 0 & 0 & 3 \\
\hline
\end{tabular}

The results are expressed as median and range with the exception of the second harmonic $(\%)$ and tachygastrias (number of patients). p-value for the difference between the groups: ${ }^{*}=0 \cdot 0002$.

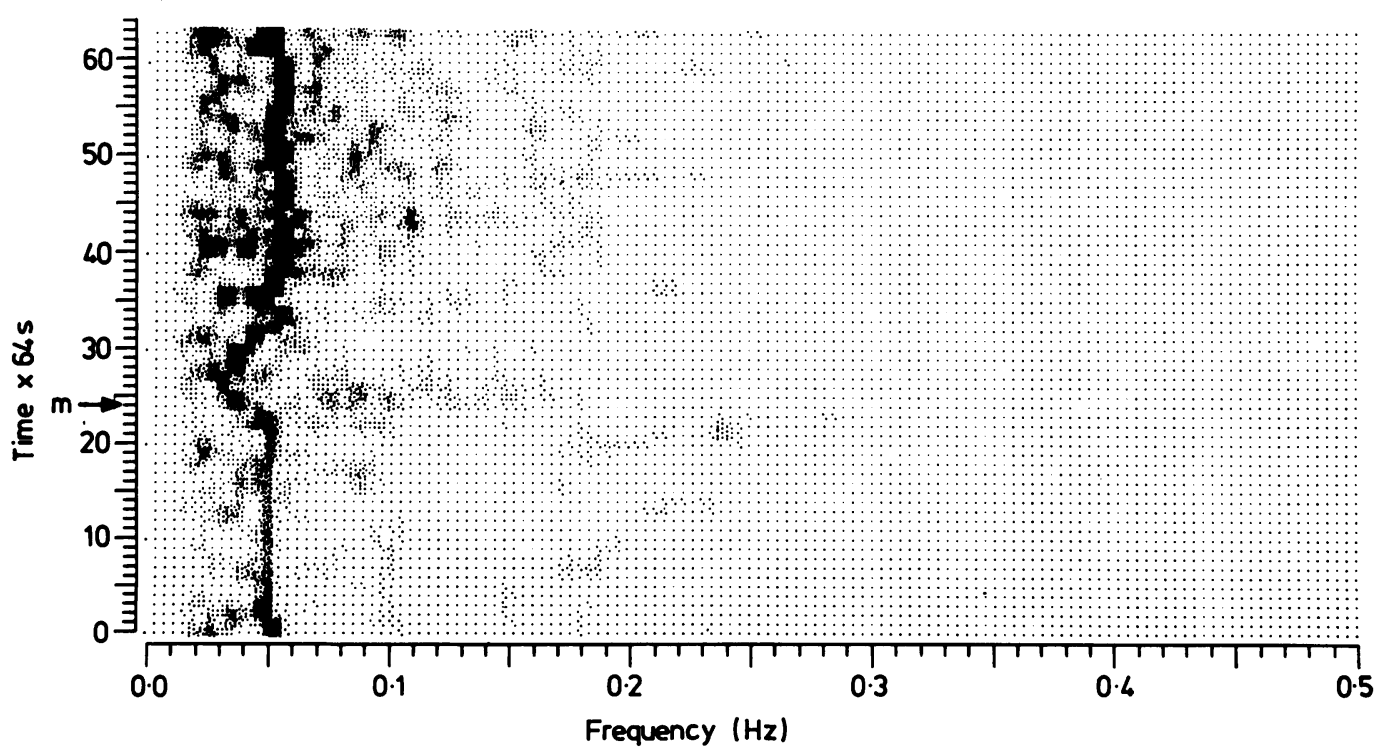

Fig. 2 Grey-scale plot of the electrogastrogram of a control subject. The blackness is proportional to the magnitude of power of the electrogastrographic signal, divided into 36 distinct grey levels. Note the frequency dip following the test meal marked with ' $M$ '. 
again, generally resulting in a temporary overshoot (Fig. 2). After that the frequency, referred to as the postprandial frequency, stabilised at a level which was at least equal to or somewhat higher than the fasting frequency. The range of the postprandial instability factor, which was the same as in the fasting state, confirmed the impression obtained by visual inspection of the grey-scale plots that the postprandial frequency was also stable. Although the power of the gastric frequency increased by at least a factor 2 after the test meal, the range of the Power Ratio indicated large inter-individual differences. A second harmonic was more often observed in the postprandial than in the fasting state. Tachygastrias were not seen in the control group. The frequency and power pattern shown in Fig. 2 was representative for this group.

Both the fasting and postprandial electrical control activity frequencies increased with age (fasting: $r=0 \cdot 78 ; p=0 \cdot 00005$, regression line: fasting frequency $(\mathrm{mHz})=0.13 \times$ age (year) +44.316 ; postprandial: $r=0 \cdot 71, p=0 \cdot 00005$, regression line: postprandial frequency $(\mathrm{mHz})=020 \times$ age $($ year $)+46 \cdot 213$ ) The remaining electrograstrographic parameters

Table 2 Electrogastrographic parameters in patients with unexplained nausea and vomiting. Normal versus delayed gastric emptying for a solid-phase meal.

\begin{tabular}{|c|c|c|}
\hline & $\begin{array}{l}\text { Patients with } \\
\text { normal gastric } \\
\text { emptying } n=17\end{array}$ & $\begin{array}{l}\text { Patients with } \\
\text { delayed gastric } \\
\text { emptying } n=13\end{array}$ \\
\hline \multirow[t]{2}{*}{ Age (yr) } & 40 & 42 \\
\hline & $19-65$ & $8-61$ \\
\hline $\begin{array}{l}\text { Duration } \\
\text { complaints (mo) }\end{array}$ & $\begin{array}{l}12 \\
4-62\end{array}$ & $\begin{array}{l}18 \\
3-60\end{array}$ \\
\hline \multicolumn{3}{|l|}{ Fasting } \\
\hline Frequency & $0 \cdot 050$ & $0 \cdot 050$ \\
\hline $\mathrm{Hz}$ & $0.045-0.059$ & $0.047-0.054$ \\
\hline Instability & $1 \cdot 22$ & 1.28 \\
\hline factor & $1.00-1 \cdot 67$ & $1 \cdot 00-1 \cdot 76$ \\
\hline Second harmonic \% & $52 \cdot 9$ & $53 \cdot 8$ \\
\hline Tachygastrias & 3 & 2 \\
\hline \multicolumn{3}{|l|}{ Postprandial } \\
\hline Frequency & 0.052 & $0 \cdot 051$ \\
\hline $\mathrm{Hz}$ & $0 \cdot 042-0 \cdot 058$ & $0.043-0.058$ \\
\hline Instability & 1.25 & 1.33 \\
\hline factor & $1 \cdot 00-2 \cdot 52$ & $1 \cdot 00-4 \cdot 00$ \\
\hline Second harmonic \% & $64 \cdot 7$ & $7 \cdot 7^{*}$ \\
\hline Power & $4 \cdot 13$ & $0 \cdot 85+$ \\
\hline ratio & $2 \cdot 09-15 \cdot 06$ & $0 \cdot 20-1.99$ \\
\hline Tachygastrias & 0 & 2 \\
\hline
\end{tabular}

The results are expressed as median and range with the exception of the second harmonic (\%) and tachygastrias (number of patients).

p-value for the difference between the groups: ${ }^{*} p=0 \cdot 002$, $t p=0.0001$. were not influenced by age, nor was there any correlation between sex and any electrograstrographic parameter.

\section{PATIENT GROUP}

The results of the electrogastrographic parameters are summarised in Tables 1,2 and 3. Several types of abnormal myoelectrical activity were observed in this group.

An unstable gastric electrical control activity frequency was seen in the grey-scale plots of some patients. Although small variations in the gastric electrical control activity frequency were observed in the control group (Fig. 2), the frequency variations observed in these patients were much more pronounced, as is illustrated in Figure 3 . These frequency variations were mainly seen in the postprandial state and were accompanied by an unstable fasting frequency in only a minority of the patients. Normally the postprandial frequency is equal or somewhat higher than the fasting frequency, but in these patients it repeatedly jumped abruptly to another, mostly lower, value (Fig. 3). The instability factor quantifies these frequency variations. In $25 \%$

Table 3 Electrogastrographic parameters in patients with unexplained nausea and vomiting after a follow-up period of one year.

\begin{tabular}{lll}
\hline & $\begin{array}{l}\text { Patients } \\
\text { without } \\
\text { complaints } \\
n=12\end{array}$ & $\begin{array}{l}\text { Patients with } \\
\text { persisting } \\
\text { complaints } \\
n=24\end{array}$ \\
& 41 & 39 \\
\hline Age (yr) & $24-66$ & $19-72$ \\
Duration & 16 & 42 \\
Complaints (mo) & $11-61$ & $16-72$ \\
Fasting & & \\
Frequency & $0 \cdot 050$ & $0 \cdot 049$ \\
Hz & $0 \cdot 046-0 \cdot 055$ & $0 \cdot 043-0 \cdot 054$ \\
Instability & $1 \cdot 17$ & $1 \cdot 41^{*}$ \\
factor & $1 \cdot 00-1 \cdot 35$ & $1 \cdot 00-2 \cdot 83$ \\
Second harmonic $\%$ & $33 \cdot 3$ & $45 \cdot 8$ \\
Tachygastrias & 0 & 6 \\
Postprandial & & \\
Frequency & $0 \cdot 054$ & $0 \cdot 052$ \\
Hz & $0 \cdot 048-0 \cdot 059$ & $0 \cdot 046-0 \cdot 055$ \\
Instability & $1 \cdot 14$ & $1 \cdot 23^{*}$ \\
factor & $1 \cdot 00-1 \cdot 33$ & $1 \cdot 05-2 \cdot 30$ \\
Second harmonic $\%$ & $66 \cdot 2$ & 50 \\
Power & $3 \cdot 55$ & $3 \cdot 07^{*}$ \\
ratio & $2 \cdot 41-15 \cdot 01$ & $0 \cdot 62-12 \cdot 32$ \\
Tachygastrias & 0 & 3 \\
\hline & & \\
\hline & &
\end{tabular}

The results are expressed as median and range with the exception of the second harmonic (\%) and tachygastrias (number of patients).

p-value for the difference between the groups: ${ }^{*} p<0 \cdot 005$. 
of the patients an instability factor was found falling far beyond the range of the instability factor in the control group.

Tachygastrias were observed in eight patients, in five cases it only occurred in the fasting state, in two only in the postprandial state, and in one patient in both the fasting and postprandial states (Figs. 4 and 5). Tachygastrias lasted between 3 and 14 minutes.

Another interesting finding was the absence of the normal postprandial power increase (power ratio $\leqslant 1$ ) in $33 \%$ of the patients. In these patients either no power change or a postprandial power decrease was observed (Fig. 6).

In all patients a frequency dip was observed identical to that found in the control group.

The patient group could be divided into two subgroups. Defining the ranges found in the control group for the postprandial instability factor and the power ratio as normal, and considering tachygastrias as abnormal, a subgroup of 25 patients could be split off in which all electrogastrographic parameters were identical to the control group (Table 1). Even the percentage of second harmonics had the same order of magnitude as in the control group. In the remaining group of 23 patients with an abnormal electrogastrogram the enlarged range of the instability factor in the fasting state can be explained by the finding that in some patients besides the postprandial, the fasting electrical control activity frequency was unstable also. It is remarkable that in this group a significant lower percentage of second harmonics was observed in the postprandial state while in the fasting state this percentage tended to be higher.

The results from the 30 patients in whom a gastric emptying study was done are summarised in Table 2. Delayed gastric emptying for solids was observed in 13 patients, who all displayed an abnormal electrogastrogram (postprandial instability factor and/or power ratio falling beyond the range of the control group and/or the presence of tachygastrias).
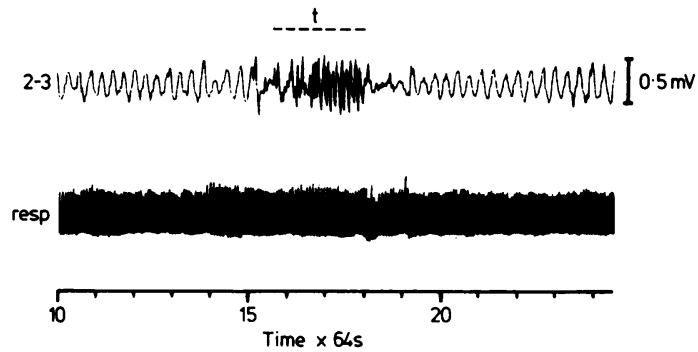

Fig. 4 Part of the bipolar time signal in the fasting state from the patient with tachygastrias both in fasting and postprandial state. The tachygastria is marked by the dashed line. Bottom trace is the respiration signal.

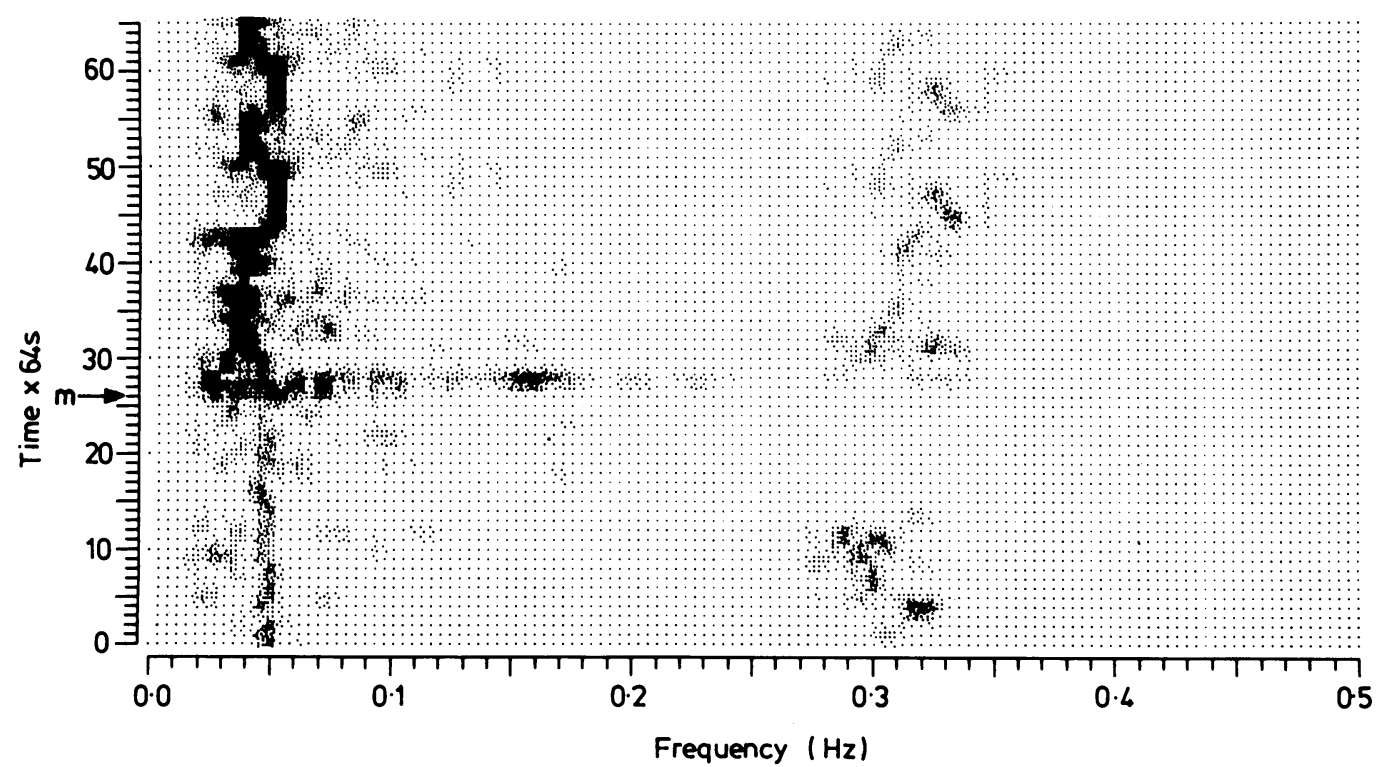

Fig. 3 Grey-scale plot of an electrogastrogram showing wide frequency variations in the postprandial state (instability factor=3.10). The frequencies at about $0.30 \mathrm{~Hz}$ are of respiratory origin. ' $M$ ' indicates the start of the test meal. 
There was a significant difference in the power ratio between patients with normal and those with delayed gastric emptying for a solid-phase meal. In the subgroup with normal gastric emptying the range of the power ratio was almost identical to the control group. With the exception of one patient (power ratio $=1.99$ ) in whom tachygastrias were observed in both the fasting and postprandial states, all patients with delayed gastric emptying showed a power decrease after the test meal (power ratio $\leqslant 1 \cdot 00$ ) (Fig. 7). It should also be mentioned that in the patient with the prolonged tachygastria in the post- prandial phase the power ratio was less than 1 . Not too much attention, however, should be paid to this finding because of the short period of normal postprandial frequency available for analysis (tachygastrias not being used for the calculation of power ratio and instability factor). The abnormally low percentage of higher harmonics observed in the postprandial state in the patients with a delayed gastric emptying should be noted.

After a follow up period of about one year 36 of the original 48 patients could be re-examined. The results of the follow up study are summarised in

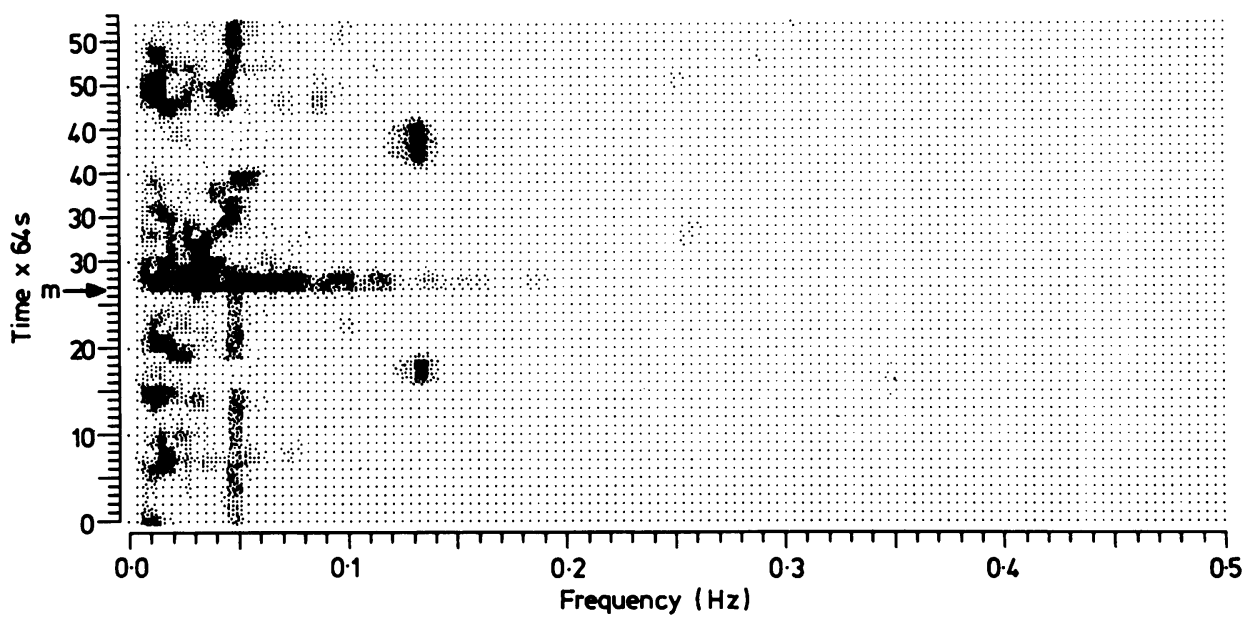

Fig. 5 Grey-scale plot of an electrogastrogram from the patient with tachygastrias both in fasting and postprandial states at about $0.13 \mathrm{~Hz}$. Coinciding with food intake (start marked with ' $M$ ') the effect of a motion artefact is visible in the spectrum. Part of the time signal in the fasting state is shown in Fig. 4.

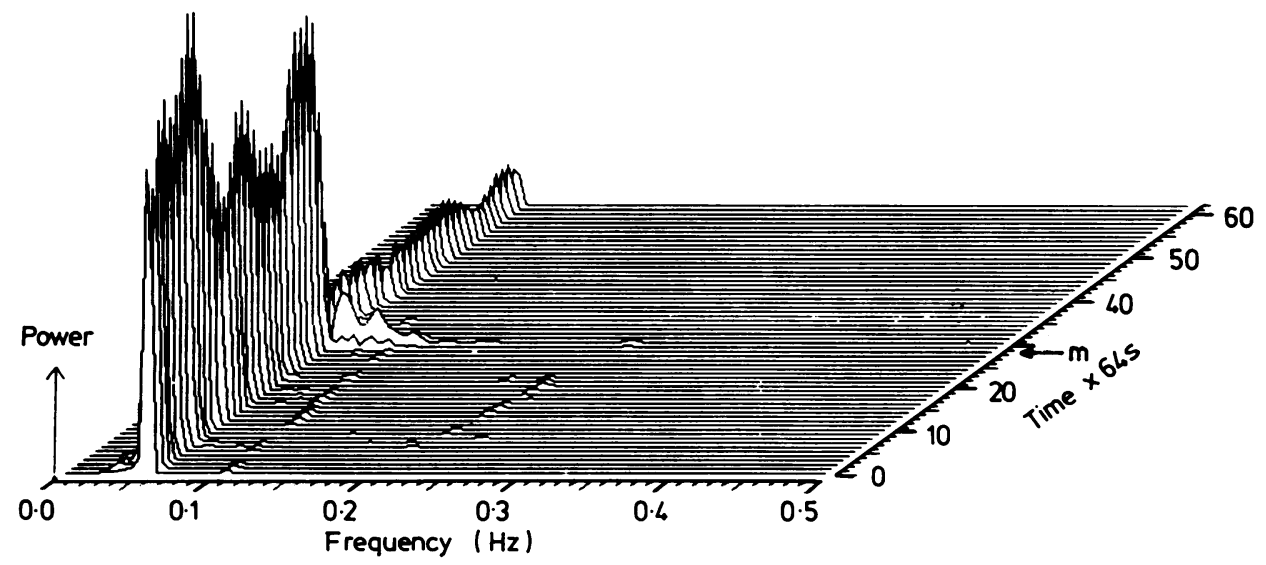

Fig. 6 Pseudo-3-D display of an electrogastrogram from a patient with a postprandial power decrease $($ power ratio=0.20). Note the second harmonic visible at about $0 \cdot 1 \mathrm{~Hz}$ in the fasting state. ' $M$ ' indicates the start of the test meal. 


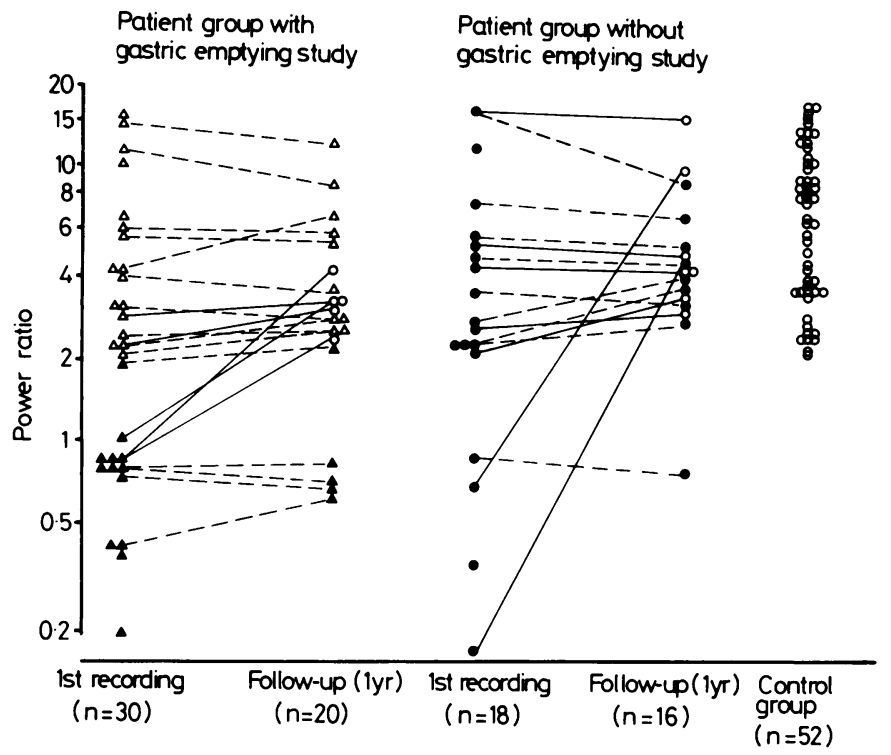

Fig. 7 Graph of the course of the power ratio in patients with unexplained nausea and vomiting. $\triangle$ : patient with nausea and vomiting and normal gastric emptying; $\boldsymbol{\Delta}$ : patient with nausea and vomiting and delayed gastric emptying; 0 : patient with nausea and vomiting; no gastric emptying study; $\bigcirc$ : patient in remission (and normal gastric emptying when this study was performed). Continuous lines in case of remission. Dotted line with persisting complaints.

Table 3. Twelve patients were free of complaints without treatment. In seven of these 12 the original electrogastrogram showed an unstable gastric electrical control activity frequency (instability factor $>2$ ) and/or an absence of the postprandial power increase (power ratio $\leqslant 1$ ). These initially abnormal electrogastrographic parameters in these 7 patients had returned to values within the range of the control group (in Fig. 7 illustrated by the power ratio). In the remaining 24 patients symptoms were still present, although practically all had benefited to a greater or lesser degree from treatment with prokinetic drugs such as metoclopramide and domperidone in combination with dietary advice. The electrogastrographic parameters in the 24 patients with persisting complaints were similar to those found in the original recording (in Fig. 7 illustrated for the power ratio).

The eight patients in whom tachygastrias had been observed initially still had tachygastrias, although the duration (range four to nine minutes) varied per patient. No abnormalities were found in the frequency dip in the follow up study.

A repeat gastric emptying study was carried out in 20 patients of whom five had experienced a symptomatic remission. In three of these five patients the initial gastric emptying was delayed and had returned to normal after one year. The initial abnormal power ratio (power ratio $<1$ ) in these three patients returned to normal as illustrated in Figure 7 . In the remaining 15 patients with persisting complaints no essential changes were found in the emptying rate, power ratio (Fig. 7) and instability factor.

\section{Discussion}

The values for the fasting and postprandial gastric electrical control activity frequencies in the control group correspond with values reported in the literature. ${ }^{8} 16$ The increase in the fasting and postprandial electrical control activity frequencies with age, observed in this study, probably explains the small differences found between the referred studies. As the mechanism and the motor correlate of the postprandial frequency dip are still unknown and the quantity and composition of the test meal may well influence the timing and frequency values of the dip, care should be taken in comparing data concerning the postprandial frequency dip. Nevertheless results from the present study are in general agreement with the literature. ${ }^{16} 2425$

In the patient group $48 \%$ of the subjects with complaints suggestive of gastric motility disorders displayed characteristic abnormalities in gastric myoelectrical behaviour. Both frequency and power abnormalities were observed in the fasting and 
postprandial states. The recorded frequency abnormalities can be divided into (1) frequency variations around the normal gastric electrical control activity frequency at about $0.05 \mathrm{~Hz}$ (Fig. 3), suggestive of a disturbed control mechanism of the gastric pacemaker, and (2) tachygastrias. Tachygastrias, a term introduced by Code and Marlett, ${ }^{26}$ are thought to be generated in an antral ectopic focus which overrides the normal gastric pacemaker. Tachygastrias were seen in eight of 48 patients. This incidence is less than reported by You et al, ${ }^{2}$ and Chey et al, ${ }^{5}$ who found tachygastrias in 9 of 14 and 35 of 70 patients respectively.

It is not known, however, to what extent the mucosal suction electrodes, used in these studies, may have given rise to tachygastrias. It should also be realised with regard to the present study that electrogastrography has its limitations in the detection of tachygastrias shorter than $64 \mathrm{~s}^{16}$ Although tachygastrias in the fasting state have been reported in the absence of any gastric symptoms, ${ }^{27}$ it is generally assumed that no motor activity is present during a tachygastria. ${ }^{1-5} 28$ This view is not in conflict with the fact that in the two patients with a postprandial tachygastria a delayed gastric emptying was observed.

The characteristic abnormality observed in the power pattern in patients was an absence of the normal postprandial power increase, or even a power decrease, after the test meal. The normal postprandial power increase in the electrogastrography signal is ascribed to the presence of electrical response activity during motor activity. ${ }^{11} 15$ In addition electrical response activity is responsible for a change in the waveform of the electrogastrogram ${ }^{15}$ which explains the increased occurrence of second harmonics in the postprandial state in control subjects. Absent or diminished postprandial motor activity and thus absent or diminished electrical response activity could be responsible for the absence of the normal postprandial power increase and the less frequent occurrence of the second harmonic in the postprandial state (Tables 1 and 2). Studies of gastric physiology $y^{29-32}$ have led to the concept that grinding and emptying of solids are primarily a function of the gastric antrum and that the rate of gastric emptying of solids is proportional to the antral phasic pressure activity generated by the meal. ${ }^{33}$ As it is antral myoelectrical activity in particular that is recorded using electrogastrography, ${ }^{15}$ 21) the observed correlation of power abnormalities with a delayed gastric emptying of solids - that is, antral hypomotility, leads us to the belief that the absence of the postprandial power increase indeed reflects a decreased postprandial electrical response activity.
This study shows that with electrogastrography in patients with unexplained nausea and vomiting abnormal myoelectrical behaviour can be discerned. In patients with an initial abnormal electrogastrogram (instability factor $>2$ ) and/or power ratio $\leqslant 1$ ), who experienced a remission of symptoms after one year, this abnormal myoelectrical behaviour had returned to normal, while in patients with persisting symptoms the myoelectrical activity remained unchanged. In a pilot study in gastric ulcer patients $^{22.34 .35}$ these same characteristic myoelectrical abnormalities were only observed in ulcer patients with nausea and vomiting. These findings suggest that electrogastrographic measurements in a heterogeneous group of patients with unexplained nausea and vomiting enable the identification of a subgroup in which abnormal myoelectrical activity is related to or even the cause of these symptoms. The observed correlation of delayed gastric emptying for solids with absence of the normal postprandial power increase, both indicative of impaired antral motor activity, supports this view. The fact that the majority of the myoelectrical abnormalities occurred postprandially underlines the importance of studying the myoelectrical activity in both the fasting and postprandial states.

The authors wish to acknowledge the assistance of Dr L M A Akkermans and the Department of Nuclear Medicine of the University Hospital of Utrecht in carrying out the gastric emptying studies.

\section{References}

1 Telander RL, Morgan KG, Kreulen DL, Schmalz PF, Kelly KA, Szurszewski JH. Human gastric atony with tachygastria and gastric retention. Gastroenterology 1978; 75: 497-501.

2 You CH, Lee KY. Chey WY, Menguy R. Electrogastrographic study of patients with unexplained nausea, bloating and vomiting. Gastroenterology 1980; 79: $311-14$.

3 You CH, Chey WY, Lee KY, Menguy R, Bortoff A. Gastric and small intestinal myoelectric dysrhythmia associated with chronic intractable nausea and vomiting. Ann Intern Med 1981; 95: 449-51.

4 Reynolds RPE, Bardakjian BL, Diamant NE. A case of antral tachygastria: symptomatic and myoelectric improvement with gastroenterostomy and domperidone therapy. Can Med Assoc J 1983; 128: 826-9.

5 Chey WY, You CH, Lee KY, and Menguy R. Gastric dysrhythmia: clinical aspects. In: Chey WY, ed. Functional disorders of the digestive tract. New York: Raven Press, 1983: 175-81.

6 Hinder RA, Kelly KA. Human gastric pacesetter potential. Site of origin, spread and response to gastric transsection and proximal gastric vagotomy. Am J Surg 1977; 133: 29-33. 
7 Sarna SK. Gastrointestinal electrical activity; terminology. Gastroenterology 1975; 68: 1631-5.

8 Brown BH, Smallwood RH, Duthie HL, Stoddard CJ. Intestinal smooth muscle electrical potentials recorded from surface electrodes. Med Biol Eng 1975; 13: 97-103.

9 Thouvenot J, Tonkovic S, Penaud J. Electrosplanchnography: method for electrophysiological exploration of the digestive tract. Acta Med Jugosl 1973; 27: 227-47.

10 Smallwood RH, Brown BH, Duthie HL. An approach to the objective analysis of intestinal smooth muscle potentials recorded from surface electrodes. In: Vantrappen G, ed. Proc 5th int symposium on gastrointestinal motility, Leuven, Belgium: Typoff-Press, 1975: 248-53.

11 Smout AJPM, van der Schee EJ, Grashuis JL. What is measured in electrogastrography? Dig Dis Sci 1980; 25: 179-87.

12 Smout AJPM, van der Schee EJ, Grashuis JL. Postprandial and interdigestive gastric electrical activity in the dog recorded by means of cutaneous electrodes. In: Christensen J, ed. Gastrointestinal motility. New York: Raven Press, 1980: 187-94.

13 Abell T, Malagelada J-R. Glucagon-evoked gastric dysrhythmias in humans shown by an improved electrogastrographic technique. Gastroenterology 1985; 88: 1932-40.

14 Bertrand J, Dorval ED, Metman EH, De Calan L, Ozour JP. Electrogastrography and serosal electrical recording of the antrum after proximal vagotomy in man. [Abstract]. Gastroenterology 1984; 86: $1(26$.

15 Volkers ACW, Van der Schee EJ, Grashuis JL. Electrogastrography in the dog: waveform analysis by a coherent averaging technique. Med Biol Eng Comp 1983; 21: 56-64.

16 Van der Schee EJ, Smout AJPM, Grashuis JL. Application of running spectrum analysis to electrogastrographic signals recorded from dogs and man. In: Wienbeck M, ed. Motility of the digestive tract. New York: Raven Press, 1982: 241-50.

17 Akkermans LMA, Jacobs F, Oei Hong You, Roelofs JMM, Wittebol P. A non-invasive method to quantify antral contactile activity in man and dog (a preliminary report). In Christensen J, ed. Gastrointestinal motility. New York: Raven Press, 1980: 195-202.

18 Jacobs F, Akkermans LMA, Oei Hong You, Hoekstra A, Wittebol P. Effects of domperidone on gastric emptying of semi-solid and solid-food. In: Towse G, ed. Progress with domperidone, a gastrokinetic and anti-emetic agent. London: Academic press, 1981: 11-20.

19 Jacobs F, Akkermans LMA, Oei Hong You, Hoekstra $A$, Wittebol P. A radioisotope method to quantify the function of fundus, antrum and their contractile activity in gastric emptying of a semi-solid and solid-meal. In: Wienbeck M, ed. Motility of the digestive tract. New York: Raven Press, 1982: 233-40.

20 Mirizzi N, Scafoglieri U. Optimal directions of the electrogastrographic signal in man. Med Biol Eng Comp 1983; 21: 385-9.

21 Smout AJPM, Van der Schee EJ, Akkermans LMA, Grashuis JL. Recording of gastrointestinal activity from surface electrodes. Scand J of Gastroenterol 1984; 19: suppl. 96: 11-18.

22 Geldof H, van der Schee EJ, Smout AJPM, Grashuis JL. Electrogastrography. In: Akkermans LMA, Johnson AG, Read NW. eds. Gastric and gastroduodenal motility. New York: Praeger Publishers, 1984: 163-75.

23 Blackman RB, Tuckey JW. The measurement of power spectra. New York: Dover Publications Inc., 1958.

24 Duthie HL, Kwong NK, Brown BH, Whittaker GE. Pacesetter potential of the human gastroduodenal junction. Gut 1971; 12: 250-6.

25 Nelson TS, Kohatsu S. Clinical electrogastrography and its relation to gastric surgery. Am J Surg 1968; 116: 215-22.

26 Code CF, Marlett JA. Canine tachygastria. Mayo Clin Proc 1974; 49: 325-32.

27 Stoddard CJ, Smallwood RH, Duthie HL. Electrical arrhythmias in the human stomach. Gut 1981; 22: 705-12.

28 You CH, Ćhey WY. Study of electromechanical activity of the stomach in humans and dogs with particular attention to tachygastria. Gastroenterology 1984; 86: 1460-8.

29 Dozois RR, Kelly KA, Code CF. Effect of distal antrectomy on gastric emptying of liquids and solids. Gastroenterology 1971; 61: 675-81.

30 Mroz CT, Kelly KA. The role of the extrinsic antral nerves in the regulation of gastric emptying. Surg Gynecol Obstet 1977; 145: 369-77.

31 Hinder RA, Kelly KA. Canine gastric emptying of solids and liquids. Am J Physiol 1977; 233: E335-40.

32 Rees WDW. Miller LJ, Malagelada J-R. Dyspepsia, antral motor dysfunction, and gastric stasis of solids. Gastroenterology 1980; 78: 360-5.

33 Camilleri M, Brown ML, Becker G, Zinsmeister AR, Malagelada J-R. Relationship between antral pressure activity and gastric emptying in man. [Abstract]. Dig Dis Sci 1984; 29: 564.

34 Geldof H, Van der Schee EJ, Van Blankenstein M, Grashuis JL. Electrogastrographic findings in patients with nausea and vomiting. [Abstract]. Gut 1983; 24: A476.

35 Geldof H, Van der Schee EJ, Van Blankenstein M, Grashuis JL. Gastric dysrhythmia; an electrogastrographic study. [Abstract]. Gastroenterology 1983; 84: 1163. 